OPEN ACCESS

Edited by:

Peng Zhang,

Zhengzhou University, China

Reviewed by:

Pengpeng Zhang,

Zhengzhou University, China

Qiuye $L i$,

Henan University, China

Xin $\mathrm{Li}$,

South China Agricultural

University, China

*Correspondence:

Taotao Ai

aitaotao0116@126.com

Zhifeng Deng

dengz@@snut.edu.cn

Specialty section

This article was submitted to Catalysis and Photocatalysis,

a section of the journal

Frontiers in Chemistry

Received: 30 January 2021

Accepted: 25 February 2021

Published: 30 April 2021

Citation:

Ai T, Fan Y, Wang $H$, Zou X, Bao W, Deng Z, Zhao Z, Li M, Kou L, Feng X and Li M (2021) Microstructure and Properties of Ag-Doped ZnO Grown

Hydrothermally on a

Graphene-Coated Polyethylene

Terephthalate Bilayer Flexible

Substrate. Front. Chem. 9:661127.

doi: 10.3389/fchem.2021.661127

\section{Microstructure and Properties of Ag-Doped ZnO Grown Hydrothermally on a Graphene-Coated Polyethylene Terephthalate Bilayer Flexible Substrate}

Taotao $\mathrm{Ai}^{1,2 *}$, Yuanyuan Fan ${ }^{3}$, Huhu Wang ${ }^{1,2}$, Xiangyu Zou ${ }^{1,2}$, Weiwei Bao ${ }^{1,2}$, Zhifeng Deng ${ }^{1,2 *}$, Zhongguo Zhao ${ }^{1,2}$, Miao Li $^{1,2}$, Lingjiang Kou ${ }^{1,2}$, Xiaoming Feng ${ }^{1,2}$ and Mei $\mathrm{Li}^{1,2}$

${ }^{1}$ National and Local Joint Engineering Laboratory for Slag Comprehensive Utilization and Environmental Technology, School of Materials Science and Engineering, Shaanxi University of Technology, Hanzhong, China, ${ }^{2}$ Shaanxi Province Engineering and Technology Research Center of Resource Utilization of Metallurgical Slag, School of Materials Science and Engineering, Shaanxi University of Technology, Hanzhong, China, ${ }^{3}$ Chengdu Hongke Electronic Technology Co., Ltd., Chengdu, China

Ag-doped ZnO nanorods growth on a PET-graphene substrate (Ag-ZnO/PET-GR) with different Ag-doped content were synthesized by low-temperature ion-sputtering-assisted hydrothermal synthesis method. The phase composition, morphologies of $\mathrm{ZnO}$, and electrical properties were analyzed. Ag-doping affects the initially perpendicular growth of $\mathrm{ZnO}$ nanorods, resulting in oblique growth of $\mathrm{ZnO}$ nanorods becoming more obvious as the Ag-doped content increases, and the diameter of the nanorods decreasing gradually. The width of the forbidden band gap of the $\mathrm{ZnO}$ films decreases with increasing Ag-doped content. For the Ag-ZnO/PET-GR composite structure, the $\mathrm{Ag}-\mathrm{ZnO}$ thin film with 5\% Ag-doped content has the largest carrier concentration $\left(8.1 \times 10^{18} \mathrm{~cm}^{-3}\right)$, the highest mobility $\left(67 \mathrm{~cm}^{2} \cdot \mathrm{V}^{-1} \cdot \mathrm{s}^{-1}\right)$, a small resistivity $(0.09 \Omega \cdot \mathrm{cm})$, and impressive electrical properties.

Keywords: ZnO, hydrothermal, doping, flexible substrate, photocatalytic

\section{INTRODUCTION}

Flexible optoelectronic devices have changed the rigid physical form of traditional devices, greatly expanded the development and application of optoelectronic devices, and widely applied in the fields of artificial skin, batteries, sensors, intelligent robots, wearable energy collectors, flexible displays, and other high-tech fields (Lou and Shen, 2015; Chortos et al., 2016; Han et al., 2017; Li et al., 2019; Wu et al., 2019; Zou et al., 2019; Liang et al., 2020; Shen et al., 2020; Zhang P. et al., 2020; Chen et al., 2021; Zhu et al., 2021). Compared to traditional devices with silicon or germanium substrates, the flexibility of newer devices is achieved via a diverse range of substrates, such as conductive polymer films (Cherusseri and Kar, 2016; Guo et al., 2016; Wang et al., 2017), ultra-thin glass (Sheehan et al., 2015), graphene (GR) (Shao et al., 2015; Zhang et al., 2020; Zhang S. et al., 2020), carbon fiber cloth (Wang et al., 2015; Zhang et al., 2021), metal foil (Yeo et al., 2016), and paper-based substrates (Sahatiya and Badhulika, 2017), with polyethylene terephthalate 

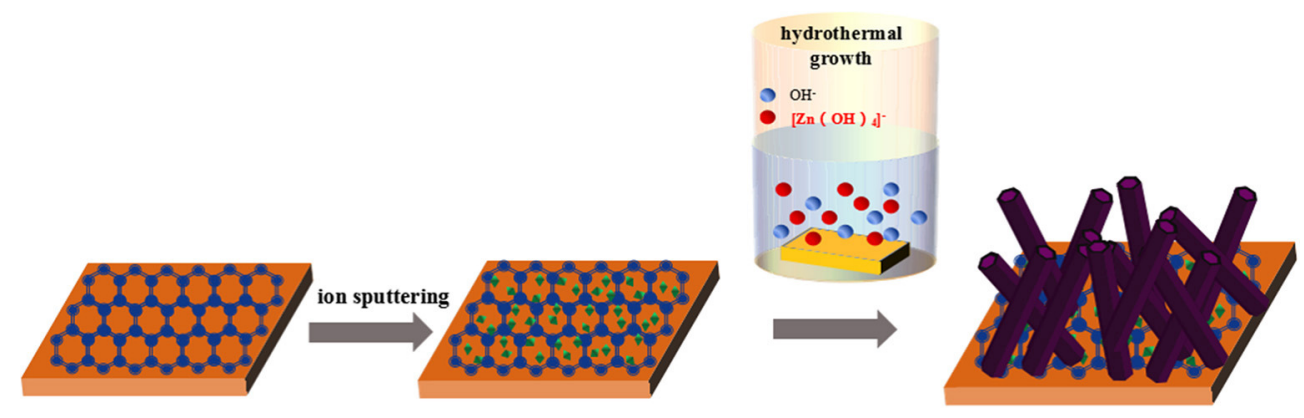

Graphical Abstract |

(PET) and GR substrates are the most representative. PET offers impressive mechanical properties, high transparency, low permeability of gas and water vapor, high transmittance in the visible light range, and higher heat resistance than other polymers (e.g., polycarbonate and polyphthalamide). Graphene demonstrates peculiar electronic and physical properties, such as high tensile strength and thermal conductivity, high absorbance, large specific surface area, and quantum Hall effect at room temperature. Furthermore, the electron mobility is 140 times that of silicon $\left(2 \times 10^{5} \mathrm{~cm}^{2} \cdot \mathrm{V}^{-1} \cdot \mathrm{s}^{-1}\right)$, an optical transmittance of 97.7\% (Pham et al., 2015), and the transparency and electrical conductivity are much better than those of indium tin oxide (ITO). A combined PET-GR composite flexible substrate, by adjusting the two kinds of structure unit and the intrinsic physical dimension constant, can exhibit excellent physical and chemical properties, realize synergy compensation, greatly expand the functionality of graphene-based applications (Liu and Lei, 2016), and effectively solve the mismatching of the thermal expansion coefficient between PET and ITO as well as the exfoliation phenomenon of ITO caused by device heating.

$\mathrm{ZnO}$, as a photoelectric material with excellent performance, has been studied extensively by researchers all over the world in recent years (Chen et al., 2016). With the development of nanotechnology, low-dimensional $\mathrm{ZnO}$ nanostructures have attracted interest as the basic unit of building flexible optoelectronic devices (Chang et al., 2012; Wang et al., 2017a,b). As the smallest dimension of electron directional transmission, one-dimensional $\mathrm{ZnO}$ nanowires have a large specific surface area, with surface states playing an important role in regulating device performance. However, because of the intrinsic defects of $\mathrm{ZnO}$, it is not suitable for direct use in devices. A common method to circumvent this limitation is to use modification treatment by element doping. Generally, n-type doping is easy to realize, there are many related studies (Wang et al., 2017a,b), and the doping technology is mature. At present, the p-type doping of $\mathrm{ZnO}$ has reached a bottleneck. As a group IB element, Ag is typically deployed in p-type doping. For example, Chen et al. (2011) prepared $\mathrm{Ag} / \mathrm{ZnO}$ nanocomposites using a solvothermal method. The experiment found that the incorporation of $\mathrm{Ag}$ not only increased $\mathrm{V}_{\mathrm{O}}$ in $\mathrm{ZnO}$, but also caused a certain amount of $\mathrm{Ag}$ deposition in the composite. Therefore, owing to the degradation of methylene blue in the catalytic experiment, the photocatalytic effect of the $\mathrm{Ag} / \mathrm{ZnO}$ nanocomposites was good. Moreover, Qin et al. (2008) found that doping with an appropriate amount of $\mathrm{Ag}^{+}$can increase the crystallinity of $\mathrm{ZnO}$ and reduce the optical band gap when studying the synthesis of $\mathrm{Ag} / \mathrm{ZnO}$ thin films by the sol-gel method. However, although the p-type doping of $\mathrm{Ag}$ is difficult owing to the self-compensation effect, the study of Ag-doped $\mathrm{ZnO}$ is essential. According to the calculation of the $\mathrm{ZnO}$ impurity level, the impurity level of Ag is close to the top of the $\mathrm{ZnO}$ valence band, which belongs to the shallow acceptor level $(0.4 \mathrm{eV})$ (Zhang et al., 2012), so it is often used for acceptor doping of $\mathrm{ZnO}$. The ion radius of $\mathrm{Ag}^{+}$ is much larger than that of $\mathrm{Zn}^{2+}$, making it easy to replace in the gap. Moreover, relative to other precious metal elements, Ag has excellent self-generation performance. Therefore, research on $\mathrm{Ag}$ doping is valuable for the preparation of high-quality $\mathrm{ZnO}$ thin films. From the perspective of materials science, the in-depth study of the properties of $\mathrm{ZnO}$-based flexible films can provide a theoretical and scientific basis for the development of high-performance flexible electronic devices (Qian et al., 2016).

In this study, Ag-doped $\mathrm{ZnO}$ nanorods grown on the double-layer film of graphene-coated polyethylene terephthalate (PET-GR) were synthesized by low-temperature ion-sputteringassisted hydrothermal synthesis method, by introducing a few amount of silver nitrate $\left[\mathrm{Ag}(\mathrm{NO})_{3}\right]$ to zinc nitrate hexahydrate $\left[\mathrm{Zn}\left(\mathrm{NO}_{3}\right)_{2} \cdot 6 \mathrm{H}_{2} \mathrm{O}\right]$ and hexamethylenetetramine $\left(\mathrm{C}_{6} \mathrm{H}_{12} \mathrm{~N}_{4}\right.$, HMTA), to investigate the photocatalysis mechanism of the Ag-ZnO/PET-GR composite structure. Our studies explore the controllable growth parameters of $\mathrm{ZnO}$ nanostructures, the relationship between process parameters and structure, and the influence of the substrate on the morphology and performance of $\mathrm{ZnO}$ nanostructures for the Ag-ZnO/PET-GR composite structure.

\section{EXPERIMENTAL SECTION \\ Synthesis of Ag-ZnO/PET-GR Composite Structure}

Ag-doped $\mathrm{ZnO}$ nanostructures grown on commercial PETGR substrate were prepared using the hydrothermal method. 
Zinc nitrate hexahydrate $\left[\mathrm{Zn}\left(\mathrm{NO}_{3}\right)_{2} \cdot 6 \mathrm{H}_{2} \mathrm{O}\right]$ of $0.5 \mathrm{~mol} / \mathrm{L}$ and $\mathrm{C}_{6} \mathrm{H}_{12} \mathrm{~N}_{4}$ of $0.5 \mathrm{~mol} / \mathrm{L}$ were dissolved in deionized water to confect $30 \mathrm{~mL}$ of precursor aqueous solution, before silver nitrate $\left(\mathrm{AgNO}_{3}\right)$ concentrations of $0,1,3,5,7$, and 9\% (where a doping concentration of $9 \%$ was defined as $0.09 \mathrm{~mol} / \mathrm{L}$ ) were added to the precursor solution, respectively. The reaction solution was stirred for $30 \mathrm{~min}$ and then transferred to a high-pressure reactor. The $\mathrm{ZnO}$ seed layer was sputtered onto a PET-GR substrate for $130 \mathrm{~s}$ using a sputtering current of $30 \mathrm{~mA}$ and vacuum degree of 0.1 mbar. The substrate adhered to the $\mathrm{ZnO}$ seed crystal was sandwiched by a specimen holder and placed vertically into an autoclave, which was completely submerged in the as-prepared mixed solution. The reactor was sealed, placed in an electric oven and heated at $90^{\circ} \mathrm{C}$ for $6 \mathrm{~h}$. The sample was removed after cooling, and the surface-attached impurities were washed with deionized water and then dried at room temperature to obtain Ag-ZnO/PET-GR films.

\section{Characterization}

The phase composition was analyzed by X-ray diffraction (XRD) using $\mathrm{Cu}-\mathrm{K} \alpha$ radiation (Rigaku, D/Max $2200 \mathrm{PC}$ ). Xray photoelectron spectroscopy (XPS) was used to study the elemental compositions at the surface and the chemical valence of the samples (ESCALAB 250Xi spectrometer, Al-Ko excitation source). The morphology of the samples was characterized using a scanning electron microscope (SEM, JEOL, JSM6700F). UV-vis absorption spectra were obtained using a double beam spectrophotometer (UV-5600PC), and the adsorption equilibrium carried out in dark condition for $12 \mathrm{~h}$. The electrical performance parameters of the Ag-ZnO/PET-GR composite structure were measured using a Hall effect tester (Hall-8800) at a temperature of $300 \mathrm{~K}$ using the Van der Pauw method.

\section{RESULTS AND DISCUSSION}

Figure 1A shows the XRD patterns of Ag-ZnO/PET-GR films with different silver nitrate doping concentrations. The peaks of all the $\mathrm{ZnO}$ samples represented in the figure are consistent with the JCPDS card standard (No. 35-1451), and the diffraction of $\mathrm{ZnO}$. The sharp diffraction peaks prove that a high-quality hexagonal wurtzite $\mathrm{ZnO}$ thin film is deposited on the flexible substrate. In addition to the miscellaneous peaks belonging to the PET-GR substrate in the XRD pattern, compared with the pure $\mathrm{ZnO} / \mathrm{PET}$-GR film, the Ag-doped $\mathrm{ZnO}$ film exhibits stronger $\mathrm{Ag}$ diffraction peaks, $\mathrm{Ag}(111)$ and $\mathrm{Ag}(200), \operatorname{Ag}(220)$, which are consistent with the Ag standard diffraction spectrum (No. 36-1451) on the JCPDS database. Specifically, no silver oxide peaks appear, and the intensity of the $\mathrm{Ag}(111)$ diffraction peak continues to increase with increasing silver nitrate doping concentrations. In order to prove that the Ag ions have been incorporated into the $\mathrm{ZnO}$ lattice successfully, XPS was used to analyze the $\mathrm{ZnO}$ film with $1 \%$ silver nitrate doping concentration ( $1 \% \mathrm{Ag}-\mathrm{ZnO}$ ). The XPS pattern of the $1 \% \mathrm{Ag}-\mathrm{ZnO}$ composite structure is shown in Figure 1B, with key peaks magnified in Figures 1C,D. In the full spectrum shown in Figure 1B, it can be clearly observed that the $1 \% \mathrm{Ag}-\mathrm{ZnO}$ composite structure contains three components: $\mathrm{ZnO}, \mathrm{Ag}$, and elemental $\mathrm{C}$. The peak may be due to the adsorption of a small amount of carbon dioxide from the air onto the surface of the sample or contamination acquired during the process of $\mathrm{C} 1 \mathrm{~s}$ detected at $290 \mathrm{eV}$. The Ag peak is weak owing to the incorporation of $\mathrm{Ag}$ ions, which have a small scattering cross section. It can be seen from the XPS spectrum in Figure 1B that the photoelectron binding energies of $\mathrm{Ag} 3 \mathrm{~d}_{5 / 2}$ and $\mathrm{Ag} 3 \mathrm{~d}_{3 / 2}$ are 367.2 and $373.2 \mathrm{eV}$, respectively. Referring to the XPS binding energy comparison table indicates that the Ag was incorporated successfully into the $\mathrm{ZnO}$ crystal lattice. Respectively, the two peaks at 1021.1 and $1044.2 \mathrm{eV}$ in the high-resolution spectrum of the photoelectron peak of $\mathrm{Zn} 2 \mathrm{p}$ (Figure $1 \mathrm{C}$ ) are attributed to $\mathrm{Zn} 2 \mathrm{p}_{3 / 2}$ and $\mathrm{Zn}$ $2 \mathrm{p}_{1 / 2}$. This indicates that $\mathrm{Zn}$ is present in the $\mathrm{Zn}^{2+}$ oxidation state. Furthermore, from the magnified peaks in Figure 1D, it can be seen that the O1s feature is mainly composed of two peaks at 529.6 and $531.2 \mathrm{eV}$, which correspond to lattice oxygen and surface hydroxyl oxygen, respectively. The surface hydroxyl oxygen can inhibit photo-generated electron-hole recombination and improve the catalytic activity. The crystal structure and elemental analysis of the Ag-ZnO/PET-GR composite structure reveals the existence of the $\mathrm{Ag}$ particles on the surface of $\mathrm{ZnO}$ and the success incorporated into its crystal lattice (Singh et al., 2017).

Figure 1 also shows FE-SEM photographs of $\mathrm{Ag}-\mathrm{ZnO}$ thin films with different silver nitrate doping concentrations $(0,1,3$, 5, 7, and 9\%) grown on PET-GR substrates. As shown in the figure, All the $\mathrm{Ag}-\mathrm{ZnO}$ nanostructures exhibit nanorod-shaped structures. As the amount of silver nitrate doping concentrations increases from 0 to $9 \%$, the diameter of the $\mathrm{Ag}-\mathrm{ZnO}$ nanorods (Ag-ZnO NRs) deposited on the PET-GR substrates gradually decreases from 140 to $41 \mathrm{~nm}$; in addition, the angle of the Ag$\mathrm{ZnO} \mathrm{NRs}$ relative to the substrate gradually increases, which is due to the continued increase of Ag-doped content. As more $\mathrm{Ag}$ nanoparticles are deposited on the sputtered $\mathrm{ZnO}$ seed layer, destroying the $\mathrm{ZnO}$ growth environment, the Ag- $\mathrm{ZnO}$ NRs cannot be deposited perpendicular to the PET-GR. As shown in Figure 1, as the doping concentration increases, the thickness of the $\mathrm{ZnO}$ nanorods in the $\mathrm{Ag}-\mathrm{ZnO} / \mathrm{PET}-\mathrm{GR}$ composite structure becomes increasingly uniform.

The growth mechanism of Ag-ZnO/PET-GR in this experiment could be described as follows. $\mathrm{Zn}\left(\mathrm{NO}_{3}\right)_{2} \cdot 6 \mathrm{H}_{2} \mathrm{O}$ provided the source of $\mathrm{Zn}$, and $\left(\mathrm{CH}_{2}\right)_{6} \mathrm{~N}_{4}$ was decomposed to provide $\mathrm{OH}^{-}$, forming the growth element. The $\mathrm{ZnO}$ crystal is composed of many monomers with a tetrahedral structure; the geometric elements revealed at the top are the vertices of many monomers, the geometric elements revealed at the side are the edges of many monomers, and the geometric elements revealed at the bottom are the surfaces of many monomers. The addition of new monomers depends on the availability of exposed hydroxides that have not been dehydrated, so to maintain the growth of the same number of the same types of monomers, growth occurs fastest at the top, followed by the side, and slowest at the bottom, then each crystal surface of $\mathrm{ZnO}$. The relationship between growth rate and magnitude is as follows: $\mathrm{V}(0001)>\mathrm{V}(01 \overline{1} \overline{1})>\mathrm{V}(01 \overline{1} 0)>\mathrm{V}(01 \overline{1} 1)>\mathrm{V}(000 \overline{1})$. In the experimental environment in this part of the study, the $\mathrm{ZnO}$ crystals grow rapidly in the (0001) direction; however, compared 

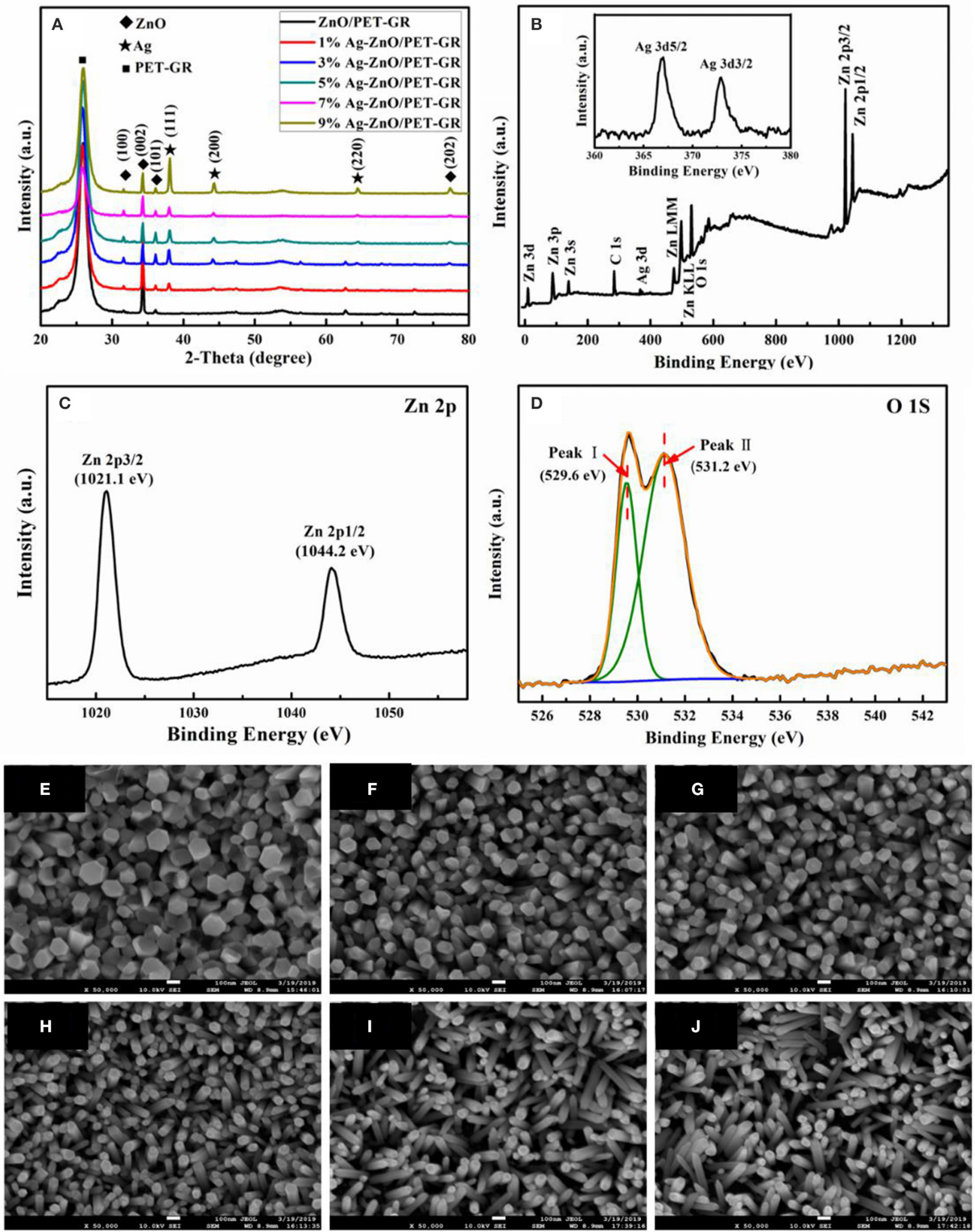

FIGURE 1 | (A) XRD patterns of Ag-ZnO/PET-GR composite structures with different silver nitrate concentrations. The inset in (A) corresponds to the Ag 3d peak; (B) XPS spectra of the Ag-ZnO thin film with a concentration of $0.01 \mathrm{M}$; (C,D) high-resolution spectra at the Zn 2p and O 1s state energies, respectively; (E-J) FE-SEM images of Ag-doped ZnO nanostructures grown on PET-GR substrate at different silver nitrate doping concentrations: (E) 0\%, (F) 1\%, (G) 3\%, (H) 5, (I) 7\%, and (J) $9 \%$. 
with the undoped $\mathrm{ZnO}$ film, the diameter of the $\mathrm{ZnO}$ nanorods in the Ag-doped $\mathrm{ZnO}$ films is significantly smaller. Moreover, there is no obvious hexagonal cross section, indicating that $\mathrm{Ag}$ doping affects the growth rate of the $\mathrm{ZnO}$ crystal planes.

In order to study the effect of silver nitrate doping concentration on the band gap of $\mathrm{ZnO}$ thin films, UV-vis absorption spectra of pure $\mathrm{ZnO}$ thin films were measured. Figure 2A shows the UV-vis light absorption spectra of $\mathrm{ZnO}$ films with different Ag-doping contents. From the figure, it can be seen that all samples demonstrate a certain amount of absorbance spanning the entire visible wavelength range, suggesting poor visible light transmission. This absorbance is attributed to the loading of Ag particles. For different silver nitrate doping concentrations, the ultraviolet-visible absorption capacity varies, with the absorption capacity determined by factors such as $\mathrm{ZnO}$ grain size and ultraviolet shielding capacity.

The UV-vis absorption spectrum assists in calculations investigating the width of the forbidden band of $\mathrm{ZnO}$ semiconductors. For intrinsic absorption, electrons absorb enough energy to jump directly from the valence band into the conduction band, and the intrinsic absorption must meet the energy of the photon. It must be equal to or greater than the forbidden band width $\mathrm{E}_{\mathrm{g}}$ of the material, and also when the frequency (wavelength) of the photon is lower (longer) than the long-wave limit of intrinsic absorption. In addition, the optical absorption coefficient of the semiconductor decreases rapidly, which appears in the transmission spectrum as the rapid increase in transmittance indicates that the absorption edge appears in the transmission spectrum. The $\mathrm{ZnO}$ semiconductor forbidden band width is calculated as follows:

$$
(\alpha h v)^{2}=A^{2}\left(h v-E_{g}\right)
$$

where $\alpha$ is the absorption coefficient, $h v$ represents the photon energy, $\mathrm{E}_{\mathrm{g}}$ is the band gap of semiconductor materials, $\mathrm{m}=$ 1 for direct band gap semiconductor $\mathrm{ZnO}$ calculation, and $\mathrm{A}$
A

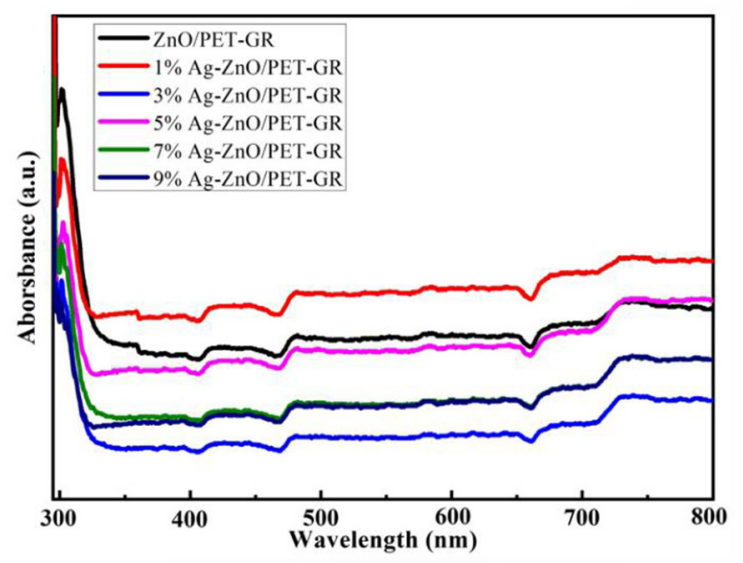

B

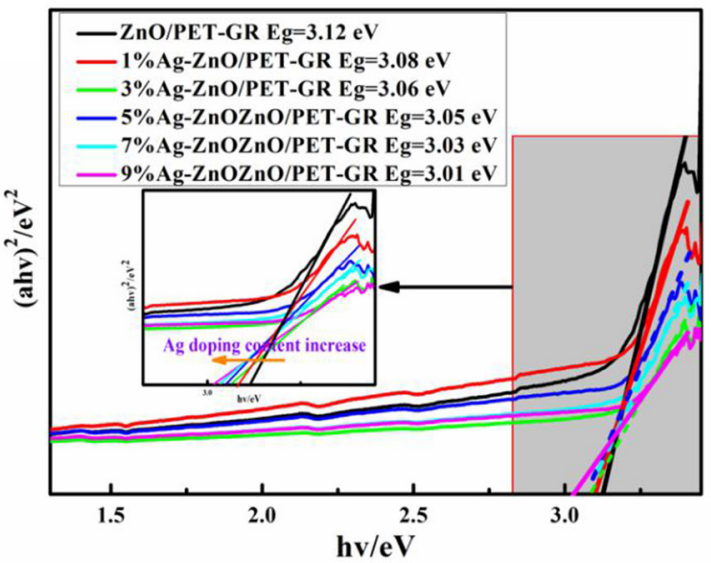

C

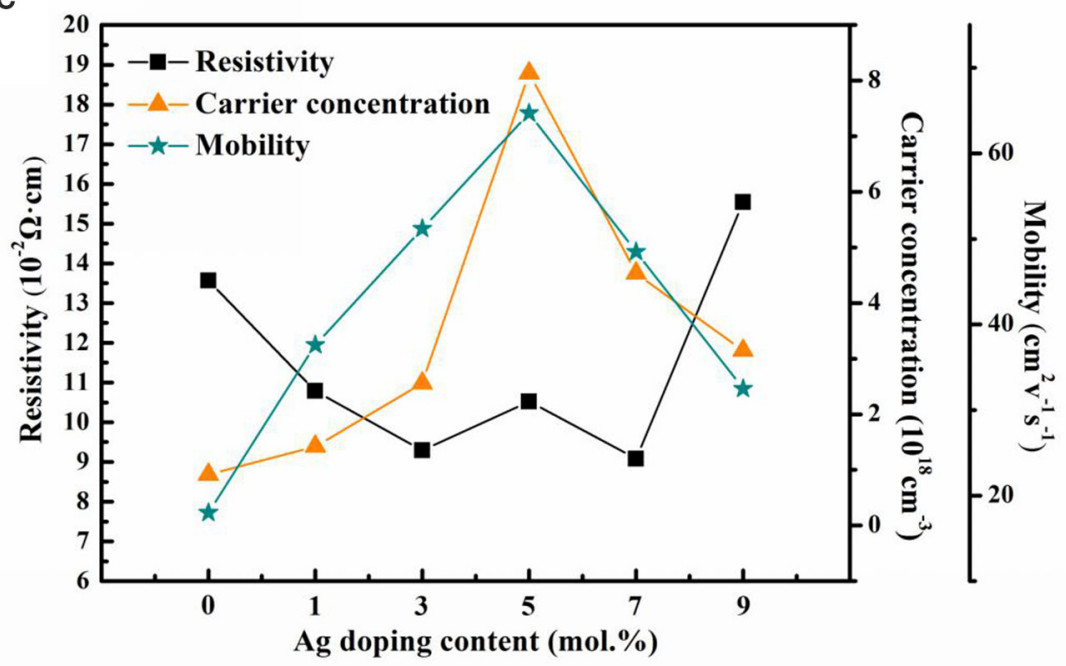

FIGURE 2 | (A) UV-vis absorption spectra of ZnO thin films with different silver nitrate doping concentrations and (B) the $(\alpha h v)^{2} \propto h v$ relationship diagram; (C) electrical properties of the Ag-ZnO/PET-GR composite structure. 
is a constant. Using the relationship based on $\mathrm{E}_{\mathrm{g}}$ (Equation 1), a tangent is drawn along the steepest part of the absorption edge in order to extrapolate to $(\alpha h \nu)=0$, with the intersection with the $\mathrm{x}$-axis corresponding to the forbidden band width value. As shown in Figure 2, based on the above steps, it can be seen that when the silver nitrate doping concentration is increased from 0 to $9 \%$, the band gap of the $\mathrm{Ag}-\mathrm{ZnO}$ film reduces from 3.12 to $3.01 \mathrm{eV}$. For the ternary alloy semiconductor material $\mathrm{Ag}_{\mathrm{x}} \mathrm{Zn}_{1-\mathrm{x}} \mathrm{O}$, the band gap $\mathrm{E}_{\mathrm{g}}(\mathrm{x})$ can be expressed as $\mathrm{E}_{\mathrm{g}}(\mathrm{x})=(1-\mathrm{x}) \mathrm{E}_{\mathrm{ZnO}}+\mathrm{xE}_{\mathrm{AO}}-\mathrm{b}(1-\mathrm{x})$, where $\mathrm{A}$ is the doping element, $\mathrm{b}$ is the band gap bending parameter, and $\mathrm{E}_{\mathrm{ZnO}}$ and $\mathrm{E}_{\mathrm{AO}}$ are the band gap energies of the $\mathrm{ZnO}$ and $\mathrm{AO}$ compounds, respectively. The addition of $\mathrm{Ag}$ to $\mathrm{ZnO}$ can change the band gap of the $\mathrm{ZnO}$-based material, which can be used as the barrier and well layers of the thin film. Thus, it is crucial for $\mathrm{ZnO}$ based devices. The Ag content of the Ag- $\mathrm{ZnO}$ film can be estimated from the relationship between the forbidden band width and the $\mathrm{Ag}$ concentration $\mathrm{xAg}$, where $\mathrm{E}_{\mathrm{g}}(\mathrm{eV})=3.12-$ $0.0122 \mathrm{xAg}$, which present a linear relationship. As the Ag content increases, the band gap of the $\mathrm{Ag}-\mathrm{ZnO}$ film becomes narrower, which is consistent with the results calculated by $\mathrm{Xu}$ and Hou (2015) using the generalized gradient approximation plane wave pseudopotential method for the Ag-doped $\mathrm{ZnO}$ model.

Through the Hall effect test, it was determined that all samples are n-type conductive, and the resistivity $(\rho)$, majority carrier concentration (n), and mobility of Ag-ZnO/PET-GR composite structure were all obtained, as shown in Figure 2C. (M) Line graph of the relationship between $\mathrm{Ag}$ and the amount of Agdoping. It is observed that as the amount of Ag-doping increases from 0 to $9 \%$, both the mobility and carrier concentration of $\mathrm{Ag}-\mathrm{ZnO} / \mathrm{PET}-\mathrm{GR}$ increase, reaching their maximum values at a concentration of $5 \%$, before decreasing at higher concentrations. This trend in the carrier concentration and mobility can be explained as follows: when the doping concentration is $<5 \%$, the increase in the Ag-doping concentration leads to more oxygen vacancies and holes in the lattice, thereby increasing the carrier concentration, while the Ag-doped also causes the $\mathrm{ZnO}$ grain boundary barrier to decrease, promoting carrier mobility. This is further evidenced by the XRD and XPS analyses.

However, after reaching a certain concentration, $\mathrm{Ag}^{+}$causes a large number of defects in the $\mathrm{ZnO}$ lattice, thereby suppressing the carrier concentration and hindering the migration of electrons, leading to decreased mobility. As the resistivity $\rho$ is inversely proportional to the majority carrier concentration (n) and mobility $(\mu)$, it increases with the silver nitrate doped concentration, in contrast to the carrier concentration and mobility trends, but its value is also $\mathrm{n}$. The carrier concentration and mobility are largest in the $5 \% \mathrm{Ag}-\mathrm{ZnO}$ film, while the resistivity is slightly higher than that of the adjacent Ag-doped $\mathrm{ZnO}$ films (i.e., the 3 and $7 \%$ films). In the application of $\mathrm{ZnO}$

\section{REFERENCES}

Chang, W. C., Cheng, Y. Y., Yu, W. C., Yao, Y. C., Lee, C. H., and Ko, H. H. (2012). Enhancing performance of $\mathrm{ZnO}$ dye-sensitized solar cells by incorporation of multiwalled carbon nanotubes. Nanoscale Res. Lett. 7:166. doi: $10.1186 / 1556-276 \mathrm{X}-7-166$ semiconductor films, it is expected that $\mathrm{ZnO}$ films have high mobility and low resistance. In the Ag-ZnO/PET-GR composite structure, the performance of Ag-doped $\mathrm{ZnO}$ films is better than that of undoped $\mathrm{ZnO}$ films. In fact, the performance is excellent, proving that Ag-doping does indeed modify the properties of $\mathrm{ZnO}$ films. Compared with other silver nitrate doping concentrations, the $5 \% \mathrm{Ag}-\mathrm{ZnO}$ film has the largest carrier concentration $\left(8.1 \times 10^{18} \mathrm{~cm}^{-3}\right)$ and mobility $\left(67 \mathrm{~cm}^{2}\right.$. $\left.\mathrm{V}^{-1} \cdot \mathrm{s}^{-1}\right)$ and a competitively low internal resistance $(0.09$ $\Omega \cdot \mathrm{cm})$. Thus, the $5 \% \mathrm{Ag}-\mathrm{ZnO} / \mathrm{PET}-\mathrm{GR}$ film offers the best overall performance.

\section{CONCLUSIONS}

In summary, Ag-doped $\mathrm{ZnO}$ thin films were fabricated successfully on a double-layer PET-GR flexible substrate using a simple low-temperature hydrothermal technique. $\mathrm{ZnO}$ nanorods were obtained. As the Ag-doping content increased, the effect of oblique growth became more obvious, and the diameter of the nanorods gradually decreased from $140-41 \mathrm{~nm}$. The forbidden band width of the $\mathrm{ZnO}$ films decreased with increasing Agdoping content. For the Ag-ZnO/PET-GR composite structure, the $5 \%$ Ag- doped $\mathrm{ZnO}$ thin film had the largest carrier concentration $\left(8.1 \times 10^{18} \mathrm{~cm}^{-3}\right)$, the highest mobility (67 $\left.\mathrm{cm}^{2} \cdot \mathrm{V}^{-1} \cdot \mathrm{s}^{-1}\right)$, a small resistivity $(0.09 \Omega \cdot \mathrm{cm})$, and good electrical properties.

\section{DATA AVAILABILITY STATEMENT}

The original contributions presented in the study are included in the article/supplementary material, further inquiries can be directed to the corresponding authors.

\section{AUTHOR CONTRIBUTIONS}

TA has put forward the proposals and supervised the whole work. YF and HW prepared materials and carried out in experiments. $\mathrm{XZ}, \mathrm{WB}, \mathrm{MiL}$, and XF helped to characterize the performances of new composites. $\mathrm{ZD}, \mathrm{ZZ}, \mathrm{LK}$, and $\mathrm{MeL}$ helped to analyze experimental data. TA accomplished the manuscript. ZD helped to check and revised. All authors contributed to the article and approved the submitted version.

\section{FUNDING}

This research was supported by the Postgraduate Innovation Fund Project of Shaanxi University of Technology, China (Grant No. SLGYCX1927).

Chen, S., Chen, Z., Chen, Q. P., Xie, H. F., Zheng, X., and Chen, X. (2011) Studies on synthesis of nano-Ag/ZnO composites using solvothermal reaction and its photocatalytic activity. Chem. World 52, 23-25. doi: 10.19500/j.cnki.0367-6358.2011.01.007

Chen, S., Lou, Z., Chen, D., Chen, Z. J., Jiang, K., and Shen, G. (2016). Highly flexible strain sensor based on $\mathrm{ZnO}$ nanowires and $\mathrm{P}(\mathrm{VDF}-\mathrm{TrFE})$ 
fibers for wearable electronic device. Sci. China Mater. 59, 173-181. doi: 10.1007/s40843-016-0128-8

Chen, Y. K., Wang, Y., Fang, J. J., Dai, B. Y., Kou, J. H., Lu, C., et al. (2021). Design of a $\mathrm{ZnO} / \mathrm{Poly}$ (vinylidene fluoride) inverse opal film for photon localization-assisted full solar spectrum photocatalysis. Chin. J. Catal. 42, 184-192. doi: 10.1016/S1872-2067(20)63 $588-4$

Cherusseri, K., and Kar, K. (2016). Ultra-flexible fibrous supercapacitors with carbon nanotube/polypyrrole brush-like electrodes. J. Mater. Chem. A 4, 9910-9922. doi: 10.1039/C6TA02690G

Chortos, A., Liu, J., and Bao, Z. N. (2016). Pursuing prosthetic electronic skin. Nat. Mater. 15, 937-950. doi: 10.1038/nmat4671

Guo, Y. L., Wang, T., Chen, F. H., Sun, X. M., Li, X. F., Yu, Z. Z., et al. (2016). Hierarchical graphene-polyaniline nanocomposite films for high-performance flexible electronic gas sensors. Nanoscale 8, 12073-12080. doi: $10.1039 /$ C6NR02540D

Han, S. T., Peng, H. Y., Sun, Q. J., Venkatesh, S., Chung, K. S., Lau, S. C., et al. (2017). An overview of the development of flexible sensors. Adv. Mater. 29, 1700375-1700396. doi: 10.1002/adma.201700375

Li, X., Yu, J. G., Jaroniec, M., and Chen, X. B. (2019). Cocatalysts for selective photoreduction of $\mathrm{CO}_{2}$ into solar fuels. Chem. Rev. 119, 3962-4179. doi: 10.1021 /acs.chemrev.8b00400

Liang, Z., Shen, R., Ng, Y. H., Zhang, P., Xiang, Q., and Li, X. (2020). A review on $2 \mathrm{D} \mathrm{MoS} 2$ cocatalysts in photocatalytic $\mathrm{H}_{2}$ production. J. Mater. Sci. Technol. 56, 89-121. doi: 10.1016/j.jmst.2020.04.032

Liu, M. J., and Lei, J. (2016). Dialectics of nature in materials science: binary cooperative complementary materials. Sci. China Mater. 59, 239-246. doi: 10.1007/s40843-016-5051-6

Lou, Z., and Shen, G. Z. (2015). Flexible photodetectors based on 1D inorganic nanostructures. Adv. Sci. 3, 1500287-1500305. doi: 10.1002/advs.201500287

Pham, V. P., Kim, K. H., Jeon, M. H., Lee, S. H., Kim, K. N., and Yeom, G. Y. (2015). Low damage pre-doping on CVD graphene/Cu using a chlorine inductively coupled plasma. Carbon 95, 664-671. doi: 10.1016/j.carbon.2015.08.070

Qian, Y., Zhang, X. W., Qi, D. P., Xie, L. H., Chandran, B. K., Chen, X., et al. (2016). Thin-film organic semiconductor devices: from flexibility to ultraflexibility. Sci. China Mater. 59, 589-608. doi: 10.1007/s40843-016-5091-1

Qin, X. J., Wang, J. N., Bu, L. M., Sun, L., Meng, H. M., Liu, R. P., et al. (2008). Effect of $\mathrm{Ag}$ and $\mathrm{Al}$ doping on structure and optical properties of $\mathrm{ZnO}$ thin films. Ordnance Mater. Sci. Eng. 31, 10-13. doi: 10.14024/j.cnki.1004-244x.2008.05.037

Sahatiya, P., and Badhulika, S. (2017). Fabrication of a solution-processed, highly flexible few layer MoS2 (n)-CuO (p) piezotronic diode on a paper substrate for an active analog frequency modulator and enhanced broadband photodetector. J. Mater. Chem. C 5, 11436-11447. doi: 10.1039/C7TC02881D

Shao, Y. L., El-kady, M. F., Wang, L. J., Zhang, Q. H., Li, Y. G., Wang, H. Z., et al. (2015). Graphene-based materials for flexible supercapacitors. Chem. Soc. Rev. 44, 3639-3665. doi: 10.1039/C4CS00316K

Sheehan, S., Surolia, P. K., Byrne, O., Garner, S., Cimo, P., Li, X., et al. (2015). Flexible glass substrate based dye sensitized solar cells. Solar Energy Mater. Solar Cells 132, 237-244. doi: 10.1016/j.solmat.2014.09.001

Shen, R. C., Ren, D. D., Ding, Y. N., Guan, Y. T., Ng, Y. H., Zhang, P., et al. (2020). Nanostructured CdS for efficient photocatalytic $\mathrm{H}_{2}$ evolution: a review. Sci. China Mater. 63, 2153-2188. doi: 10.1007/s40843-020-1456-x

Singh, S. K., Singhal, R., and Siva Kumar, V. V. (2017). Study on swift heavy ions induced modifications of $\mathrm{Ag}-\mathrm{ZnO}$ nanocomposite thin film. Superlattices Microstruct. 103, 195-204. doi: 10.1016/j.spmi.2017.01.032

Wang, A. L., He, X. J., Lu, X. F., Xu, H., Tong, Y. X., and Li, G. R. (2015). Palladiumcobalt nanotube arrays supported on carbon fiber cloth as high-performance flexible electrocatalysts for ethanol oxidation. Angew. Chemie Int. Edn. 127, 3740-3744. doi: 10.1002/ange.201410792

Wang, T., Guo, Y. L., Wan, P. B., Sun, X. M., Zhang, H., Yu, Z., et al. (2017). A flexible transparent colorimetric wrist strap sensor. Nanoscale 9, 869-874. doi: 10.1039/C6NR08265C
Wang, W., Ai, T. T., Li, W. H., Jing, R., Fei, H., and Feng, X. (2017a). Photoelectric and electrochemical performance of $\mathrm{Al}$-doped $\mathrm{ZnO}$ thin films hydrothermally grown on grapheme-coated polyethylene terephthalate bilayer flexible substrates. J. Phys. Chem. C 121, 28148-28157. doi: 10.1021/acs.jpcc.7b08181

Wang, W., Ai, T. T., Yu, Q. (2017b). Electrical and photocatalytic properties of boron-doped $\mathrm{ZnO}$ nanostructure grown on PET-ITO flexible substrates by hydrothermal method. Sci. Rep. 7:42615. doi: 10.1038/srep42615

Wu, Y. Y., Zhang, L. L., Zhou, Y. Z., Zhang, L. L., Li, Y., Liu, Q., et al. (2019). Light-induced $\mathrm{ZnO} / \mathrm{Ag} / \mathrm{rGo}$ bactericidal photocatalyst with synergistic effect of sustained release of silver ions and enhanced reactive oxygen species. Chin. J. Catal. 40, 691-702. doi: 10.1016/S1872-2067(18)63193-6

$\mathrm{Xu}, \mathrm{Z}$. C., and Hou, Q. Y. (2015). GGA+U study on the effects of Ag doping on the electronic structures and absorption spectra of ZnO. Acta Phys. Sin. 64:157101. doi: 10.7498/aps.64.157101

Yeo, H. G., Ma, X. K., Rahn, C., and Trolier-Mckinstry, S. (2016). Efficient piezoelectric energy harvesters utilizing (001) textured bimorph PZT films on flexible metal foils. Adv. Funct. Mater. 26, 5940-5946. doi: 10.1002/adfm.201601347

Zhang, P., Li, Y., Zhang, Y., Hou, R., Zhang, X., Xue, C., et al. (2020). Photogenerated electron transfer process in heterojunctions: in situ irradiation XPS. Small Methods 4:2000214. doi: 10.1002/smtd. 202000214

Zhang, S., Zhang, P., Hou, R., Li, B., Zhang, Y., Liu, K., et al. (2020). In situ sulfurdoped graphene nanofiber network as efficient metal-free electrocatalyst for polysulfides redox reactions in lithium-sulfur batteries. J. Energy Chem. 47, 281-290. doi: 10.1016/j.jechem.2020.01.033

Zhang, S., Zhang, Y., Shao, G., and Zhang, P. (2021). Bio-inspired construction of electrocatalyst decorated hierarchical porous carbon nanoreactors with enhanced mass transfer ability towards rapid polysulfide redox reactions. Nano Res. 14, 1-10. doi: 10.1007/s12274-021-3319-x

Zhang, X. D., Guo, M. L., Shen, Y. Y., Liu, C. L., Xue, Y. H., Zhu, F., et al. (2012). Electronic structure and optical transition in heavy metal doped $\mathrm{ZnO}$ by first-principle calculations. Computat. Mater. Sci. 54, 75-80. doi: 10.1016/j.commatsci.2011.10.003

Zhang, Y., Zhang, P., Li, B., Zhang, S., Liu, K., Hou, R., et al. (2020). Vertically aligned graphene nanosheets on multi-yolk/shell structured TiC@C nanofibers for stable Li-S batteries. Energy Storage Mater. 27, 159-168. doi: 10.1016/j.ensm.2020.01.029

Zhu, P. F., Yin, X. H., Gao, X. H., Dong, G H., Xu, J. K., and Wang, C. Y. (2021). Enhanced photocatalytic NO removal and toxic $\mathrm{NO}_{2}$ production inhibition over ZIF-8-derived $\mathrm{ZnO}$ nanoparticles with controllable amount of oxygen vacancies. Chin. J. Catal. 42, 175-183. doi: 10.1016/S1872-2067(20)63 $592-6$

Zou, Z. M., Yang, X. Y., Zhang, P., Zhang, Y. M., Yan, X. X., Zhou, R. M., et al. (2019). Trace carbon-hybridized $\mathrm{ZnS} / \mathrm{ZnO}$ hollow nanospheres with multi-enhanced visible-light photocatalytic performance. J. Alloys Compounds 775, 481-489. doi: 10.1016/j.jallcom.2018. 10.116

Conflict of Interest: YF was employed by company Chengdu Hongke Electronic Technology Co., Ltd.

The remaining authors declare that the research was conducted in the absence of any commercial or financial relationships that could be construed as a potential conflict of interest.

Copyright (๔ 2021 Ai, Fan, Wang, Zou, Bao, Deng, Zhao, Li, Kou, Feng and Li. This is an open-access article distributed under the terms of the Creative Commons Attribution License (CC BY). The use, distribution or reproduction in other forums is permitted, provided the original author(s) and the copyright owner(s) are credited and that the original publication in this journal is cited, in accordance with accepted academic practice. No use, distribution or reproduction is permitted which does not comply with these terms. 